Article

\title{
A Systemic Perspective for Understanding Digital Transformation in Higher Education: Overview and Subregional Context in Latin America as Evidence
}

\author{
Luis Manuel Cerdá Suárez ${ }^{1, *(1)}$, Karen Núñez-Valdés ${ }^{2}$ and Susana Quirós y Alpera ${ }^{1}$ \\ 1 Faculty of Business and Communication, School of Engineering, \\ Universidad Internacional de La Rioja (UNIR), 26006 Logroño, La Rioja, Spain; susana.quiros@unir.net \\ 2 Faculty of Education, Universidad de Las Américas, Av. Manuel Montt, 946, Sede Providencia, \\ Santiago 7500975, Chile; k.nunez.valdes@gmail.com \\ * Correspondence: luis.cerda@unir.net
}

Citation: Cerdá Suárez, L.M.; Núñez-Valdés, K.; Quirós y Alpera, S. A Systemic Perspective for Understanding Digital Transformation in Higher Education: Overview and Subregional Context in Latin America as Evidence. Sustainability 2021, 13, 12956. https://doi.org/10.3390/ su132312956

Academic Editors:

Fabrizio D'Ascenzo, Carlos HervásGómez, María Dolores Díaz-Noguera, Pedro Román-Graván and María de los Ángeles Domínguez-González

Received: 1 October 2021

Accepted: 16 November 2021

Published: 23 November 2021

Publisher's Note: MDPI stays neutral with regard to jurisdictional claims in published maps and institutional affiliations.

Copyright: (c) 2021 by the authors. Licensee MDPI, Basel, Switzerland. This article is an open access article distributed under the terms and conditions of the Creative Commons Attribution (CC BY) license (https:// creativecommons.org/licenses/by/ $4.0 /)$.

\begin{abstract}
Since virtual education has increased from a local to a global audience, it is of great importance to understand the role that cultural and social backgrounds play in the transition to digital education. Therefore, a review of preferences and evidence among different Latin American regions and nations increases understanding. This digital transformation can be assessed under several categories of cultural, social, and economic situations. Traditionally, universities are known as formal institutions with emerging education trends, but it is mandatory to address the managerial work and implications of the institutions themselves. Particularly, universities play a relevant role in understanding the effective digital transformation in communities, but the profile of the educational system is very important for configuring this process. This research points out the main dimensions that prevent societies from increasing their educational level. By using comparative data analysis and documentary references, this paper highlights a systemic perspective for understanding the digital transformation in higher education, but it also expands the range to managerial decisions about the role educational ecosystems play in this transformation. Moreover, this study provides an overview of how relational elements configure management in higher education institutions.
\end{abstract}

Keywords: digital transformation; higher education; Latin America; systemic perspective; crosscultural comparison

\section{Introduction}

Since digitalization developed (AI, artificial intelligence; IoT, Internet of Things; cloud computing solutions; among others) [1,2], information and communication technologies have focused on disruption and innovation [3,4], including operational activities with a creative dimension, such as gamification, machine learning, virtual and augmented reality, and videogames [3]. Moreover, the pandemic and the different approaches taken by governments to enact a lockdown have accelerated the volatility, uncertainty, complexity, and ambiguity (VUCA) across the political, social, economic, and technological environment $[5,6]$.

Induced by social and technological trends towards digitalization [7], universities have been experiencing a set of relevant changes. The adoption of technologies by universities is related to a paradigm shift [8,9], where technology is configured as a complex environment that enables digital learning, facilitating several learning experiences, improving teaching materials, and the training process in general [9-11]. Due to this factor, educational institutions rise as relevant actors of innovation [12].

This investigation refers to the digital transformation as a requirement in higher education institutions [12,13], presenting evidence of the relevance and impact that it has in the Latin American context. The authors identify the main disruptive technologies by 
researching how models and processes of institutions are being transformed, generating deep but somehow fragile changes. From this assertion, we describe the challenges, risks, opportunities, and guidelines that universities in Latin America must face to address their own digital transformation. Digital transformation is considered inevitable $[9,14,15]$ and must be approached with a clear understanding of each institution's peculiarities [16,17]. Additionally, this paper sketches out different ideas about the role that higher education institutions in Latin America could play to make contributions in building a sturdier society and what piece institutions are putting into practice to act as relevant facilitators of this change.

According to [9,18-20], digital transformation must be set, regarding a systemic perspective, to contribute to meeting the expectations of different interest groups in the cultural, social, economic, and environmental dimensions. For instance, from the economic point of view, digital transformation offers diverse benefits, such as more profitable business models, more efficient operating processes, enhanced value propositions, automated processes, and lower cost of exchange of information [21]. This consideration is becoming pertinent for universities, as competition to select the best students and researchers is increasing, according to sustainable management. Additionally, the social dimension that affects digital transformation is focused on the student's experience and how digitalization improves by replacing traditional educational models and services. What is more, this phenomenon is considered to be a resource to create additional, differentiated value, integrating digital technologies into teaching, learning, and institutional practices.

From a cultural point of view, Pedroza [22] points out that learning can be sorted into three wide epistemological frameworks: objectivism, pragmatism, and interpretivism. While objectivism reveals that reality is external to the mind and understanding is acquired experientially, pragmatism defends that knowledge is a tradeoff between action and inquiry. Nevertheless, interpretivism considers knowledge as an internal construction through socialization and cultural cues. Following a systemic perspective, a fourth framework supported by Siemens [23] indicates that knowledge is composed of linked entities, that is, an emergent, connected, and adaptive knowledge related to the epistemological framework for undergoing the digital transformation in higher education [24,25].

In [26], the authors evaluated different components regarding digital transformation in higher education. Research on this topic is an iterative process that requires continued efforts to ensure the soundness of the phenomenon when applied to various populations and settings. Hence, the re-evaluation of existing measurement instruments is common.

Correspondingly, the matter of this research is to comprehend whether social, organizational, and technological aspects are linked to the interest generated by the digital transformation in higher education institutions [24], or, conversely, to present the multiplicity of perspectives in which this digitalization has been addressed among different Latin American regions and nations. While the digital transformation in higher education institutions is an emerging field that has aroused interest during recent years [25], little is known about how it operates in several regions and areas. To conceptualize the systemic perspective for understanding this phenomenon, there is a need for information. Utilizing this approach, this research explores how the adoption of technologies by universities offers a framework for understanding digitalization.

Most studies on digital transformation in higher education are focused on the need for strengthening digital strategies to reinforce the use of technologies as a part of the digital agenda for Latin America and the Caribbean (LAC). This paper, however, deals with a novel topic describing a holistic view of the context of higher education in Latin America [26]. Such a view can be used as a conceptual framework and as evidence for exploring the initiatives proposed in the region. The intention of this research is to provide a relatively simple framework by drawing concepts touched on in the literature on digital transformation in higher education in Latin America. The conceptualization that we developed is related to teaching and learning, but draws mainly on the literature of what has come to be called the systemic perspective in higher education. 
Therefore, considering higher education institutions as an ecosystem in practice, the following research question was identified to explore the issues exposed previously: Is it possible to measure a systemic perspective in the digital transformation of higher education?

Based on references with a focus on regional ecosystems, our specific objectives are the following:

(1) Establish a systemic framework regarding digital transformation in education;

(2) Exhibit evidence of digital transformation according to this systemic perspective.

The outline of this manuscript is as follows. First, a background, conceptual framework, and research agenda are constructed. Second, a methodological design and procedure are described. Third, an additional section is devoted to results and discussion, and finally, contributions, conclusions, implications, limitations, and further research are presented.

\section{Systemic Background on Digital Transformation in Higher Education}

For decades now, digital transformation in education has been implemented worldwide [27], paying attention to helping students with digital tools that can be reachable wherever there is an online computer terminal. Saving time and resources by means of online management and tuition seems to be the emerging challenge.

Digital transformation is an action that gathers all digital aspects and calls for adjustments in technology, culture, and institutions. Therefore, according to [28], digital transformation in higher education does not merely refer to a technological transformation.

In this way, digital transformation must be analyzed from a systematic perspective. This perspective will be able to understand how the different actors operate in the development of digital transformation, specifically in higher education. From this perspective, it is possible to establish challenges and obstacles that emerge in the transformation process and the plausible methods of improvement [29]. This type of analysis allows us to understand how the system works and the interactions between its components [30,31]. In short, a systemic perspective increases opportunities for change, as emerging conclusions can become a catalyst for existing opportunities [32,33].

Countries like Finland, Korea, and Estonia spent several decades implementing their educational reforms [7]. Evidence from LAC and their institutions paints a relevant picture for analysis. Despite sharing cultural aspects, LAC is extremely vast in territory and population, but overpopulation in big cities, dispersion of such population, unequal access to technology, and diverse demographic distributions are social and cultural realities of particular interest in the region. In addition, curriculum adaptations, online grading, alumni relationships, among others, are shared aspects with a high potential to be changed by digital transformation.

Higher education institutions in LAC are well-rooted, but processes, management structures, decision procedures, and educational methodologies are very focused on traditional measures, which have proven not to be effective. On the one hand, every country has a different context, but they all share the need to update the use of Information and Communication Technologies at various levels. On the other hand, nowadays, there are basic tools for analysis, decisions, tracking, and assessment based on real-time, multi-sourced information dashboards that require the integration of several user groups, including not only students and professors but also academic managers, content providers, and the wider society in the region.

In LAC, universities are at the core of knowledge, research, and innovation and are the driving forces of development in the region. Their permanent relationship with the environment aids in measuring the relevance and the extent of the response to the requirements of society. Technology must be part of the solution, but it cannot replicate or exacerbate the learning divide. Given the difficulties the region has had in providing education during the pandemic, pervasive socio-economic differences exist among students, such as inequality in access to technology, connectivity, and digital resources, with most of the region's students outside their classrooms [7]. According to data from the 2018 Programme for International Student Assessment (PISA), less than half of students from 
low socio-economic backgrounds in the region lived in an environment that was ready to engage in remote learning. Only 30\% had computers for schoolwork, and less than half had internet access; almost all students from wealthy backgrounds had access to computers $(95 \%)$ and the internet (98\%).

In LAC, radio and TV have been the most common technologies used to reach students and deliver education. According to a review of the 23 countries in LAC that closed their schools because of the pandemic, 74 percent used radio and TV, 52 percent made digital content available, and 35 percent combined textbooks with social media to continue learning during the crisis. Only Uruguay was able to move schools online with digital platforms that cover the school curriculum and allow teachers to communicate with students and monitor their learning progress $[7,9]$.

Considering what was proposed by [29], we briefly present the background of digital transformation related to higher education in Latin America and the Caribbean in six dimensions:

(a) The framework of a system of (a) all premises and (b) strategic choices that guide the specification and reification of the other five dimensions). Historically, according to [34], the university's role evolved from a former metaphysical role, through research-driven scientific advancements in the service of economic development for further optimizing its own self-interest, to a brand-new ecological role ("the university for others"). According to [34] "automation will make many jobs obsolete before long"; therefore, higher education institutions must meet the pace of digital transformation to survive and furthermore deliver their subjects in a more flexible way.

Information is key for social development [35], and higher education institutions play the role of conveying it to society by using effective tools and strategies after thorough managerial work is performed by teachers. The digital information transformation challenge, according to universities, asks for an adaptation to societal needs. In this scenario, digital policies acquire great relevance to enhance the opportunities offered by digitization. These policies should be part of the agendas of the universities, but more importantly, of the digital agenda of each country. In LAC, there is a need for governments to work on this matter, since at present, only 16 of the 27 countries have digital agendas in force and in implementation, while 11 require reform or update. These agendas are more linked to the economy than to other areas [36], making digitization processes more complex in the rest of the institutions.

The need for adaptation of higher education institutions in the region has been manifested with greater force due to the COVID-19 pandemic since the internet and associated technologies have become essential instruments to continue educational activities during the crisis, which shows the need for an agenda that considers educational institutions as a priority for the development of the country [36].

(b) The scope of the system specifies (a) its domain and (b) its function. Induced by social and technological trends towards digitalization [7], universities have been experiencing a set of relevant changes. As for the adoption of technologies by universities, it is related to a paradigm shift [8], where technology is configured as a complex environment that enables digital learning, facilitating several learning experiences, improving teaching materials, and the training process in general [10]. Due to this factor, educational institutions rise as relevant actors of innovation [12]. The digital transformation is a requirement in higher education institutions [13]. In Latin America and the Caribbean, a study revealed that the use of digital platforms in universities was a reality in the period prior to the pandemic, since $80 \%$ of the institutions had a platform for distance education, increasing this number by $8 \%$ after the COVID-19 crisis, which shows the set of changes that these institutions are experiencing in the region [37]. It was due to the incorporation of technologies that the universities continued with their functions in the period of confinement in the different countries of the region. 
(c) The structure of the system specifies (a) its primary constituents, i.e., physical or conceptual entities inside the system that significantly affect its operation and outcomes, and (b) how these constituents interact with (or relate to) each other: The reality of Latin America presents great challenges to the governments of the region because these are called to include the technology development of each country in their national policies in accordance with the requirements of globalization, which shows the existing tension between the characteristics of LAC and its abilities to respond to an adverse context. For example, in the peak period of the COVID 19 crisis, less than half of Latin Americans had experience using computers and digital skills for basic professional tasks. For this reason, more than half of the region's population was excluded from remote activities [38]. This situation revealed the great inequalities that exist around the access and use of technologies.

(d) The ecology of a system specifies that (a) all primary agents in its environment and (b) how the system and environment interact with (or relate to), and affect, each other. The vision of educational managers and the role that teachers assume in a higher education institution have a great impact on the digital transformation since the incorporation of content, new teaching modalities and interactions between the different actors depend on them [39]. In LAC, the balance between the actors in the system is fragile due to problems in the region such as (i) limited internet access, (ii) lack of digital skills in teachers and students, and iii) the inability of servers to support bulk data traffic [40]. These situations have contributed to the difficulties in taking advantage of the use of digital platforms and have shown inequality in terms of access to education, especially in the pandemic period [37].

(e) The operation of a system is about all processes and/or the system as a whole, which might be engaged on their own and/or under external intervention from the environment of the system in order to serve the function of the system following specific rules of engagement. In Latin America and the Caribbean, there is a need for states to invest in technological infrastructure that allows the development of universal digital transformation; that is, technology should reach all sectors and groups in the country without distinction of their economic position. By 2019, only five countries in the region (Argentina, Brazil, Chile, Mexico, and Uruguay) have developed, or are developing, government-led AI policies and strategies [38]. The OECD indicates that there are seven specific areas in which countries must take measures so that the digital transformation seeks the growth and well-being of the region to (1) improve access to digital technologies, (2) strengthen their effective use, (3) enable digital innovation, (4) guarantee good quality jobs for all, (5) promote an inclusive digital society, (6) strengthen trust, and (7) encourage market opening [41].

(f) The outcomes of a system consist of all actual products, events, and phenomena (and/or services, when the system is, say, of social or industrial nature), which the system brings about (reified purposes) on its own or in concert with other systems. LAC has had to face the crisis caused by the coronavirus (COVID-19), which entails the impossibility of physical contact due to the quarantine period that was implemented in different countries [42]. This new reality made digital technologies a priority, especially because they enabled part of the population and companies to continue studying and working while sanitary measures were complied with. For international organizations, the global pandemic "made inclusive digital transformation a top priority to mitigate the negative effects and accelerate economic recovery of countries [43]. Likewise, the pandemic revealed difficulties that organizations with low levels of digital maturity have had to face, which have had to work in a context of adversity, uncertainty, and fragility [6], testing the capacity to adapt to global economies. It is expected that the forms of teaching and learning that have started as emergency formulas to guarantee pedagogical continuity will evolve and become consolidated to contribute to the change of the universities in the region [37]. 
Latin America and the Caribbean is a diverse region, in terms of its history and culture, yet it shares the same difficulties and threats on the road to digital transformation. Several authors point out that this challenge must be faced from a cross-cultural perspective that prioritizes institutional dynamics, capable of paving the way for the region to fully insert itself in the new world scenario [44].

This cross-cultural view allows self-recognition of the strengths and opportunities that exist to face the new challenges associated with digital transformation and places the different territories of the region as lived places that can contribute knowledge from their own experience [45].

\section{Materials and Methods}

In order to appreciate the relevance of the above-mentioned background of the study, the present work was performed in two stages: the first one was based on conceptual work and a literature review, particularly through documentaries and secondary sources. The second stage applied a quantitative methodology to analyze the final data.

In empirical terms, the research presented in this paper is part of the larger international project regarding the results of the Open Consultation carried out by the International Association of Universities (IAU) between November 2018 and April 2019 [46]. On the one hand, the starting point of the research was this IAU report as a secondary source focused on the context in which higher education institutions operate in an environment conducive to digitalization worldwide. On the other hand, in this paper, further research uncovered other results and findings focused on the infrastructure and governance, followed by a section looking at changes as they relate to teaching and learning in order to know the current state of digitalization and to inform the development of a new IAU Policy Statement worldwide, and particularly in LAC.

\subsection{Participants and Sample}

In this project, an Expert Advisory Group was established and composed of IAU Board members and experts from different parts of the world in higher education leadership as well as specific areas of digital transformation [46]. With the aim to measure the digital transformation in higher education from a systemic perspective in LAC, the data collection was divided into two separate consultations: (1) leaders in higher education institutions (i.e., leadership consultation based on the desire to reach out to the leadership of these institutions), and (2) representatives across the institution (that is, comprehensive consultation) because they could facilitate information from as many different sectors as possible within institutions involved in activities related to digital transformation.

The IAU World Higher Education Database (WHED Portal, www.whed.net, accessed on 23 November 2020) configured the more relevant source of information to reach out to higher education institutions worldwide. In collaboration with UNESCO, the IAU WHED Portal provides information on higher education systems in 196 countries and territories, and over 20,000 higher education institutions. For this research, heads of institutions and representatives received an invitation to participate in the consultation through their national networks, including the Commonwealth of Learning (COL), the European University Association (EUA), the Association of Universities of Latin America and the Caribbean (UDUAL), the Association of African Universities (AAU), the Groningen Declaration Network (GDN), and the Conference of Rectors of Universities (CRUE) in Spain. As a member of the CRUE in Spain, the Universidad Internacional de La Rioja (UNIR) is an online university setting in Spain, Colombia, Ecuador, México, Perú, and recently in the United States, offering education for students who come from all over LAC and other countries worldwide.

\subsection{Measurements and Data Collection}

In this research, the purpose of the open consultation and data collection consisted of the following four distinct phases [46]: (1) identification through a range of experiences 
of stakeholders; (2) documentation to make visible the individual's experiences; (3) an assessment of these experiences; and 4) certification of the results leading to a partial or full qualification. As an instrument to collect information, consulting stakeholders in terms of their views, perceptions, and experiences in the open consultation helped to identify that all relevant evidence was considered, including data about antecedents and the benefits of the research initiative; in this context, validation could be understood as a process of confirmation by experts.

Given the exploratory nature of this study, the participants in this research were selected from a diversity of higher education institutions as a form of triangulation to improve the validity of the research by collecting geographically distributed data. This data collection process of extreme sampling considered opinions and perceptions that represented the main ongoing changes of educational practices regarding digitalization and the specific context on each situation, rather than being solely a reflection of the current educational systems.

Based on a subregional assessment and several criteria, including digital maturity, international rankings, and the progress achieved in digital transformation, among others, this initiative included a diagnosis of the current situation in Argentina, Brazil, Chile, Colombia, Costa Rica, the Dominican Republic, Ecuador, Mexico, Paraguay, Peru, Trinidad and Tobago, and Uruguay. The aim was to provide a general overview of information about initiatives in this area and topics regarding some elements of the digital ecosystem in higher education.

An analysis of the data was carried out to better understand the information contained in the datasets. Due to the partnership with CRUE, the data came from the first edition of the initiative participating UNIR. As a member of the CRUE, a research group was commissioned by the institution to participate in this project. The datasets were anonymized, and the data analysis was performed based on the variables included in the study.

\subsection{Information Sources and Methodology}

First, in empirical terms, the IAU report presented the results of the consultation showing a worldwide overview of facts and figures. Focused on documentary analysis and information shared by experts for each country [46], we analyzed the following sources and methods: (1) a summary of the country profile was analyzed as a general context; (2) the documentation of the digitalization efforts made by stakeholders in higher education, and civil society to strengthen the ecosystem in Latin America; and (3) a general overview. Given the exploratory character of this research, answers from respondents were collected (data collection procedure) with the following information regarding each ecosystem:

Part I: institutional and contextual elements linked to digital transformation. Two variables were identified, (1) the framework of a system and (2) the scope of the system.

Part II: digital transformation in higher education at institutions, regarding two aspects, (1) the structure of the system and (2) its ecology.

Part III: perceptions of the implementation of digital transformation in higher education, measured by (1) the operation of a system and (2) its outcome.

The study focused on the graphic visualization and descriptive and numerical analysis of the results regarding the relationship between categorical variables (Part I and Part II). Categories were defined, and frequencies were obtained from the results of the relationships proposed. Several scales were defined with a Likert-type scale ranging from 1 strongly disagree to 10 strongly agree (Part III). At the same time, we described the perceptions of the participants with the geographical region of their institution for comparison.

Second, to further investigate the data in LAC regarding the perceptions of the implementation related to digital transformation (Part I, Part II, and Part III), we studied descriptive analyses among all variables according to the next section. In addition, the association between the perceptions of the participants and the geographical regions and subregions was tested by making statistical contrasts in operational terms. To that end, we used Pearson's chi-squared test and, to evaluate the strength of a relationship after a statis- 
tically significant association was revealed, we also performed a contingency coefficient and Cramer's V test. In this research, the Mann-Whitney and Kruskal-Wallis tests were used to compare populations, contrasting whether the perceptions of participants differed significantly (in all cases, we tested the null hypothesis $\mathrm{H}_{0}$ : There is no association between the institution's perceptions and the region being considered. Hypothesis $\mathrm{H}_{0}$ was tested by making statistical contrasts between the associational relationships of all variables).

\section{Results and Discussion}

In this section, although the analyses were quantitative in nature, the main aim is to provide a general framework to aid in the qualitative interpretation of the results. Thus, it is important to describe the empirical insights for further exploration and discussion. First, regarding the data analysis, a worldwide overview will be described, and second, the focus will be particularly on LAC.

In this section, Tables 1-3 and their descriptions are referred to in the above-mentioned IAU report [46]. According to the methodological process described in this study, Table 1 shows the profile and distribution of replies worldwide (descriptive statistics). IAU received a total of 1039 complete replies from 127 countries (replies by region are listed below).

Table 1. Number of respondents by region.

\begin{tabular}{lccccccc}
\hline & Africa & Asia and the Pacific & Europe & LAC & Middle East & North America & Total \\
\hline $\begin{array}{c}\text { Leadership } \\
\text { consultation }\end{array}$ & 70 & 75 & 119 & 43 & 27 & 347 \\
\hline $\begin{array}{l}\text { Comprehensive } \\
\text { consultation }\end{array}$ & 146 & 186 & 202 & 38 & 117 & 3 & 692 \\
\hline Total & 216 & 261 & 321 & 81 & 144 & 16 \\
\hline & Source: Adapted from [46].
\end{tabular}

Table 2 shows the profile of respondents by gender and age distribution worldwide (total, comprehensive consultation). In terms of gender, $32 \%$ were women, and $68 \%$ were men. As shown in this table, a high proportion of respondents were $<56$ years old $(76 \%)$.

Table 2. Profile of respondents by gender and age distribution (worldwide).

\begin{tabular}{cccccccccc}
\hline & \multicolumn{1}{c}{ Profile of Respondents by Gender } & \multicolumn{5}{c}{ Profile of Respondents by Age Distribution } \\
\hline & Female & Male & $<25$ & $26-35$ & $36-45$ & $46-55$ & $56-65$ & $66-75$ & $>75$ \\
\hline \multirow{2}{*}{ Total } & $32 \%$ & $68 \%$ & $2.5 \%$ & $17.7 \%$ & $30.8 \%$ & $25 \%$ & $20.6 \%$ & $3.2 \%$ & $0.2 \%$ \\
\hline \multicolumn{4}{c}{ Source: Adapted from [46]. }
\end{tabular}

Table 3 shows the demographic statistics of the participants at the institution in LAC (profile). In this analysis, it is possible to note the differences and similarities among public, private-for-profit, and private-not-for-profit institutions (in a slower way in LAC compared to other regions for public institutions: $50 \%$ versus $61 \%$ ), the high proportion of institutions predominantly teaching focused in LAC (21\% versus $15 \%)$, as well as the similar proportion of institutions teaching bachelors between LAC and worldwide (89\%).

Table 3. Demographic statistics: LAC versus Total (worldwide).

\begin{tabular}{cccccccccc}
\hline & \multicolumn{3}{c}{ Type of Institution } & \multicolumn{3}{c}{ Profile of Institution } & \multicolumn{2}{c}{ Degree Offered by the Institution } \\
\hline Public & $\begin{array}{c}\text { Private-not- } \\
\text { for-profit }\end{array}$ & $\begin{array}{c}\text { Private- } \\
\text { for-profit }\end{array}$ & $\begin{array}{c}\text { Teaching and } \\
\text { research }\end{array}$ & $\begin{array}{c}\text { Teaching } \\
\text { focused }\end{array}$ & $\begin{array}{c}\text { Research } \\
\text { focused }\end{array}$ & $\begin{array}{c}\text { BSc } \\
\text { degree }\end{array}$ & $\begin{array}{c}\text { Master's } \\
\text { degree }\end{array}$ & $\begin{array}{c}\text { Doctoral } \\
\text { degree }\end{array}$ \\
\hline LAC & $50 \%$ & $32 \%$ & $18 \%$ & $76 \%$ & $21 \%$ & $3 \%$ & $89 \%$ & $81 \%$ & $70 \%$ \\
\hline Total & $61 \%$ & $21 \%$ & $18 \%$ & $83 \%$ & $15 \%$ & $2 \%$ & $89 \%$ & $92 \%$ & $69 \%$ \\
\hline \multicolumn{3}{c}{ Source: Adapted from [46]. }
\end{tabular}




\subsection{Evidencing Digital Transformation in Higher Education: A General Overview}

Regarding the above-mentioned methodology of the study, in this subsection, we describe the conditions for understanding context and the dimensions regarding the governance of institutions worldwide, as revealed by the IAU report [46].

In terms of the framework of a system, participants were asked to fill in a questionnaire about their general opinions regarding the usage of national research education network and the digital transformation. Figure 1 describes the bar charts of stakeholders' perceptions of these situational aspects for different categories (from a = yes, use of national research education network, to $\mathrm{d}=$ not applicable). In the comprehensive consultation, regarding the question: 'Usage of national research education network at the institution', the region weighing higher on the negative side of the scale was LAC $(29 \%)$, where most respondents considered the usage of the national research networks less conducive to digital transformation (that is, adding 'no'; Figure 1).

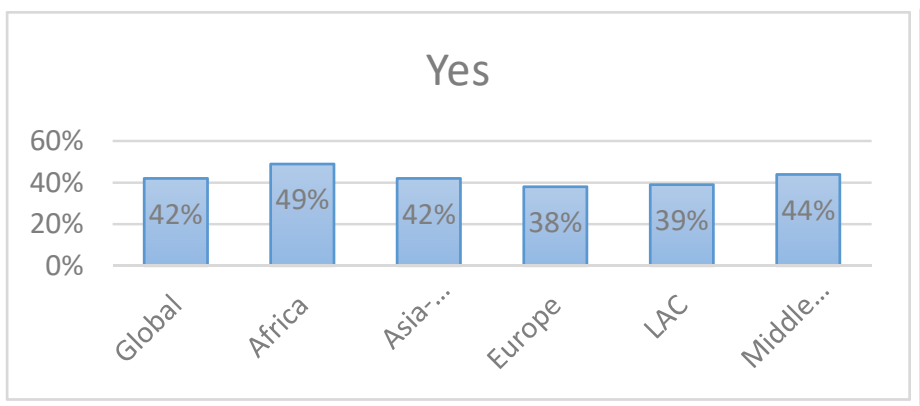

(a)

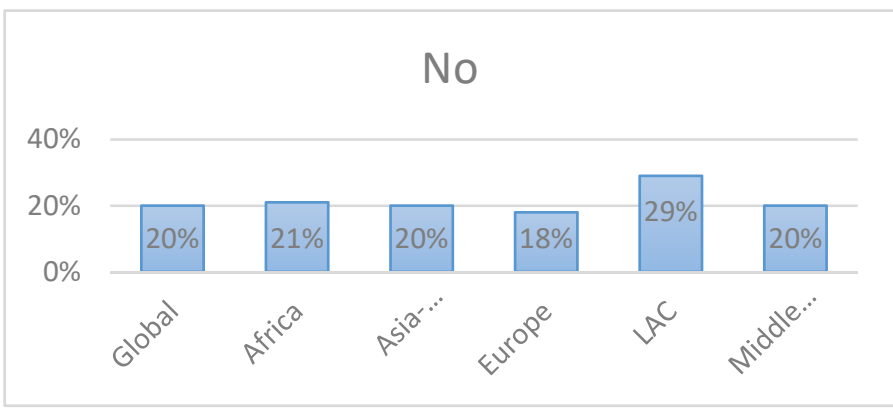

(b)

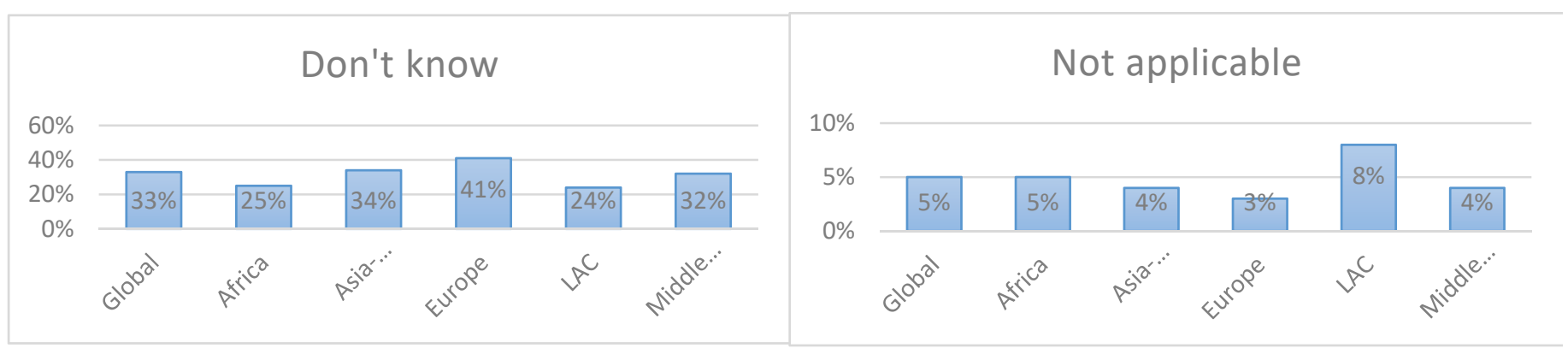

(c)

(d)

Figure 1. Usage of national research education network. Source: Adapted from [46]. (a) Yes, use of national research education network at the institution; (b) No; (c) Don't know; (d) Not applicable.

In terms of the scope of the system, respondents were asked about their general perceptions regarding the commitment to widening access to higher education (Figure 2 shows the bar charts of participants' opinions to these aspects for four categories). In terms of leadership consultation, respondents were questioned with a focus on commitment and the situation for higher education institutions. In this sense, there was a relevant difference between Europe (26\% described 'not at this stage'), and LAC (37\% said 'yes, fully'). Certainly, this consideration suggests that the challenges are not the same among regions (Figure 2).

Additionally, in the comprehensive consultation, respondents were also asked to describe the structure of the system regarding digital transformation within the institution. According to the above-mentioned theoretical background described in this work, the structure of the system specifies its primary constituents and how these constituents interact with (or relate to) each other. Thus, the same entities, their constituents, and their components can result in different structures and utilities (i.e., function) depending on how they are related to each other. Figure 3 shows participants' opinions regarding the 
structure and utility of the learning management systems in terms of the usage of learning management systems at institutions, measured by how these systems interact and operate in experiential learning (response categories from $\mathrm{a}=$ yes, very much, fully engaged, to $\mathrm{d}=$ no, not at this stage). The results illustrate the different situations regarding the specific context of analysis: the respondents in Europe indicated that structure was relevant (33\%) in contrast to LAC (16\%: 'Yes, very much, fully engaged'; Figure 3).

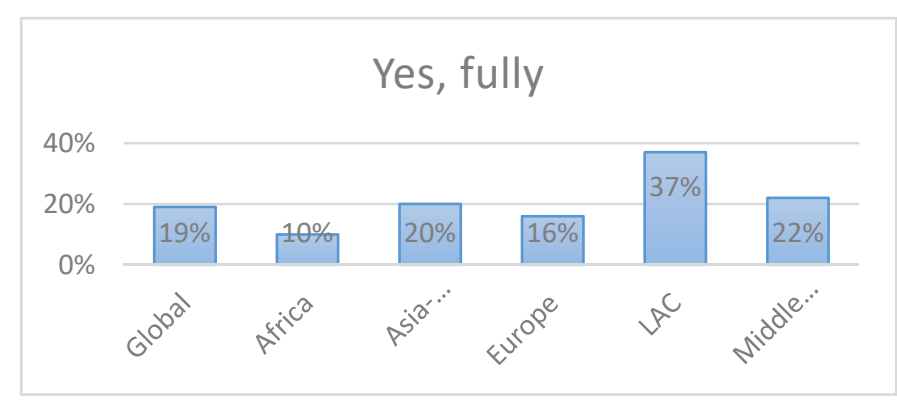

(a)

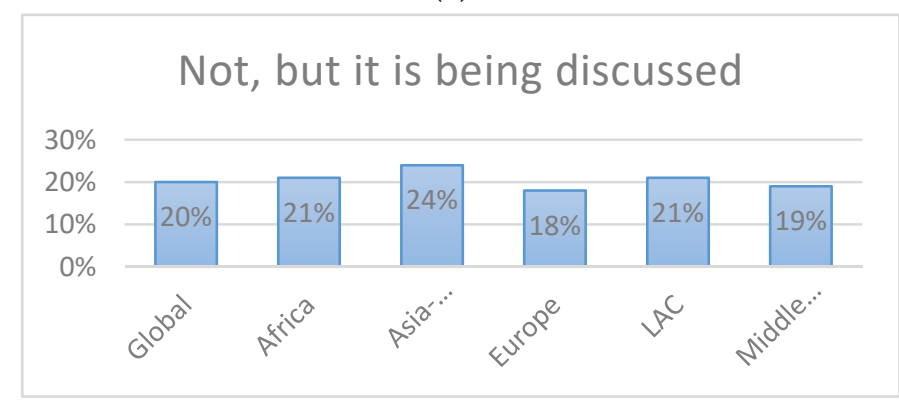

(c)

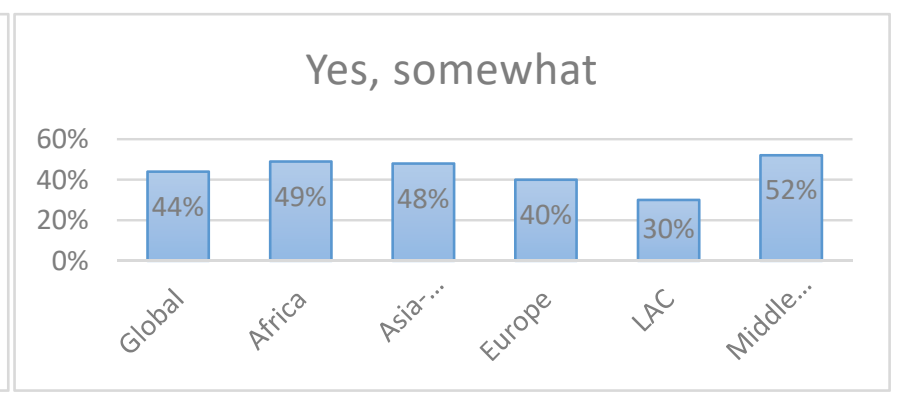

(b)

\section{No, not at this stage}

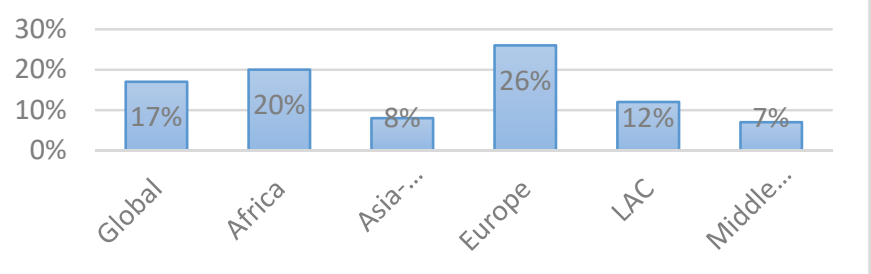

(d)

Figure 2. Relevance of the commitment to widening access to higher education. Source: Adapted from [46]. (a) Yes, fully committed to widening access to higher education; (b) Yes, somewhat; (c) Not, but it is being discussed; (d) No, not at this stage.

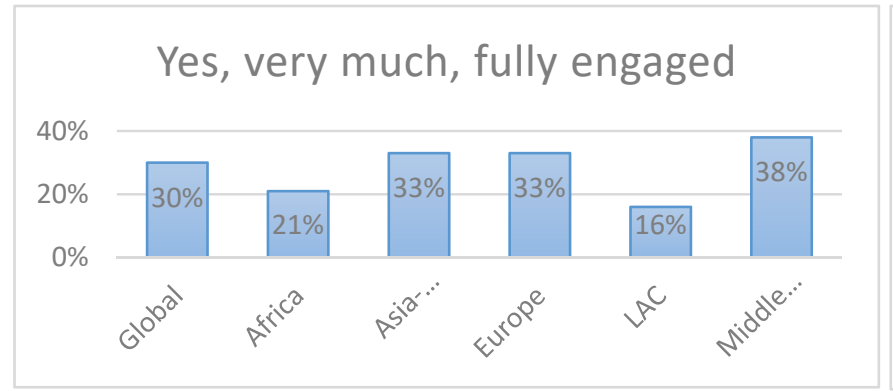

(a)

\section{Yes, to some extent}

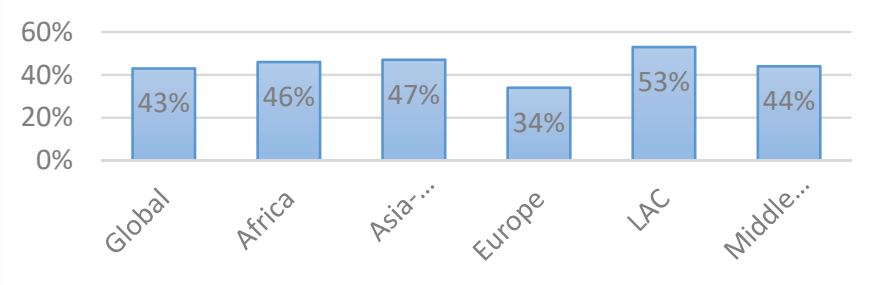

(b)

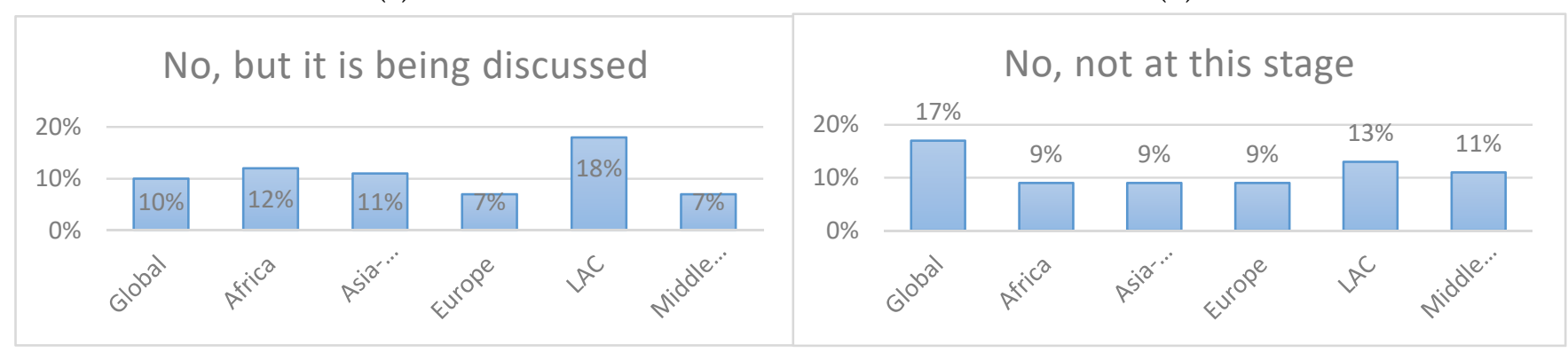

(c)

(d)

Figure 3. Relevance of the usage of learning management systems at institutions. Source: Adapted from [46]. (a) Yes, very much, fully engaged; (b) Yes, to some extent; (c) No, but it is being discussed; (d) No, not at this stage. 
Respondents were asked about their general perceptions regarding the ecology of digital transformation in higher education, in terms of changes in teaching pedagogies, competencies, and assessments at institutions. Figure 4 shows the bar charts of participants' opinions to this consideration for all answer categories (from a = have changed a lot, to $\mathrm{d}=$ are not changing). In the comprehensive consultation in relation to the query: 'In the past five years, changes in teaching pedagogies, competencies, and assessments have occurred', two answer categories stand out, followed by LAC and Europe (79\% and 81\% respectively), as shown in Figure 4. The second one was related to the perception that pedagogies are not changing, whereas LAC shows the lowest result for this answer $(0 \%)$.

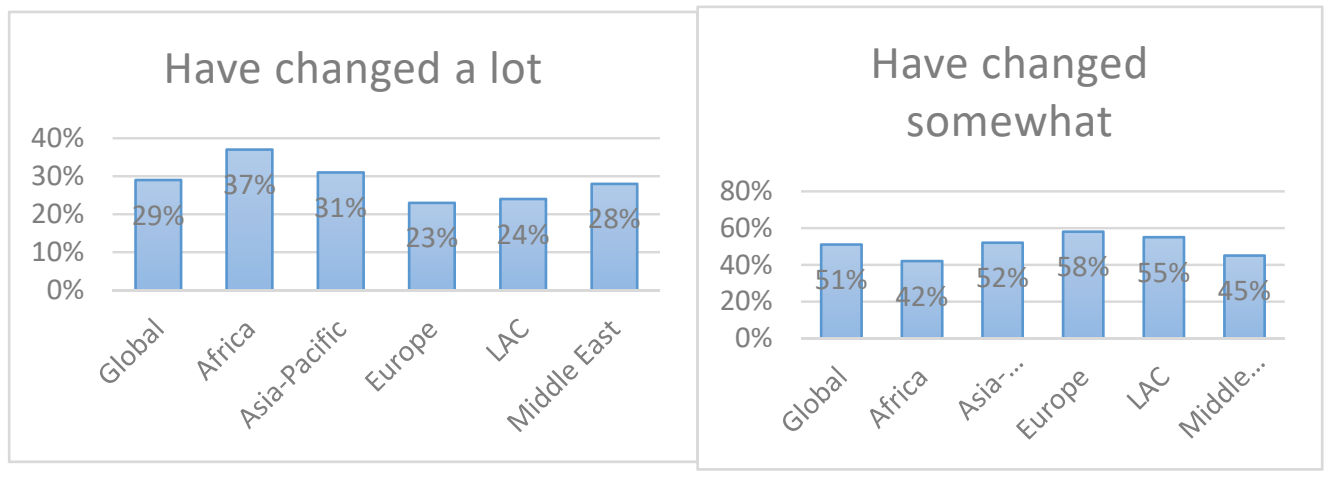

(a)

(b)

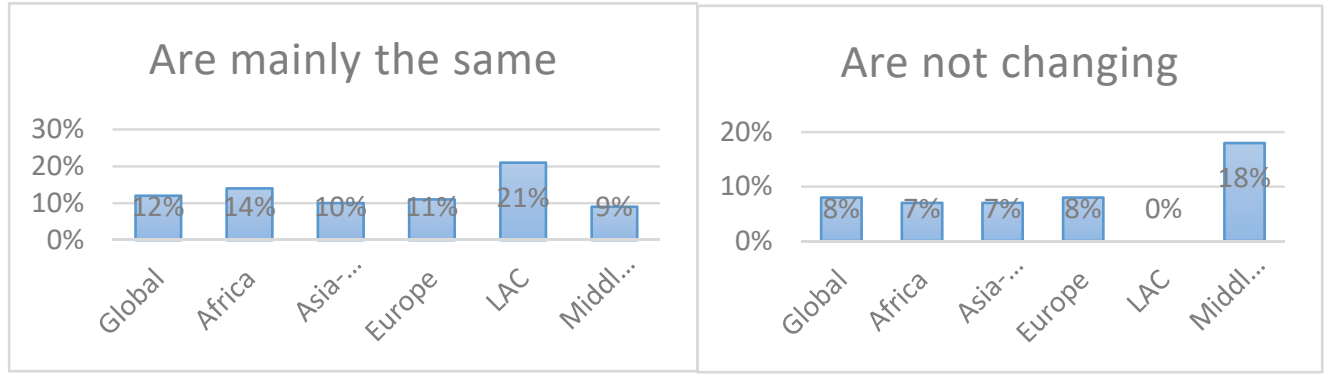

(c)

(d)

Figure 4. Changes in teaching pedagogies, competencies, and assessments. Source: Adapted from [46]. (a) Teaching pedagogies have changed a lot; (b) Teaching pedagogies have changed somewhat; (c) Teaching pedagogies are mainly the same; (d) Teaching pedagogies are not changing.

In the comprehensive consultation regarding how a system operates through the creation, use, and development of infrastructure for open educational resources, the respondents were asked about perceptions of the implementation of digital transformation (Figure 5 shows the bar charts of participants' opinions for four response categories in terms of national initiatives in favor of open educational resources). In this category, Asia-Pacific $(22 \%)$ and Europe $(62 \%)$ were above the global average. Globally, $6 \%$ stated 'no, not at all', and in this category, the LAC were above the global average $(10 \%)$. 


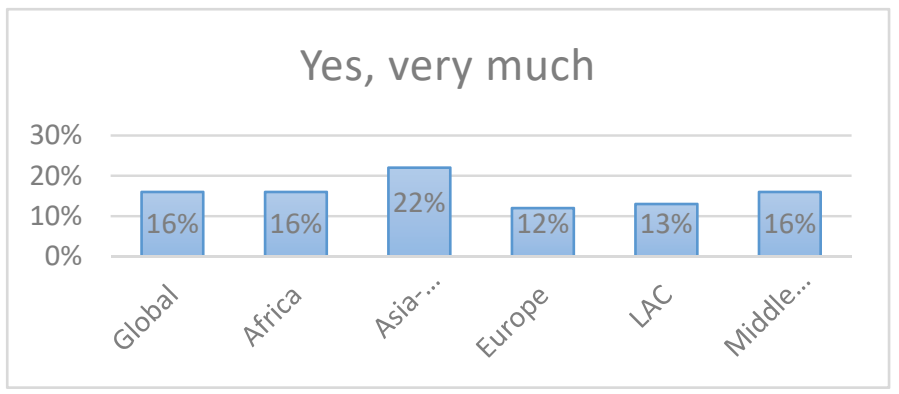

(a)

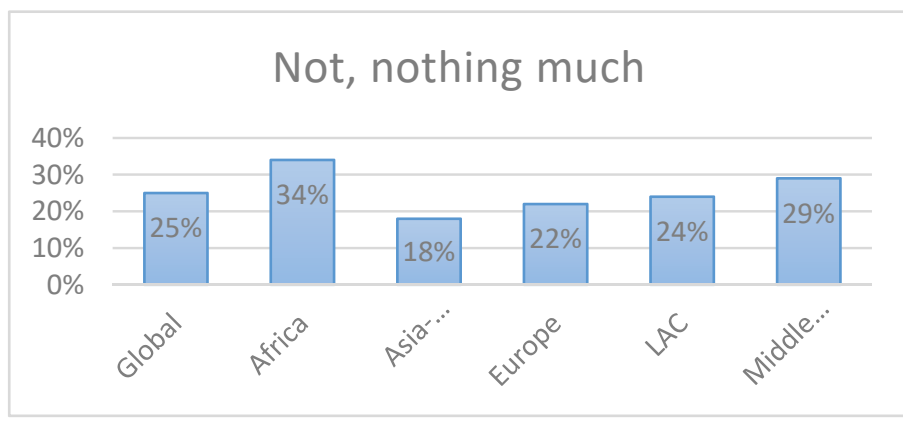

(c)

\section{Yes, somewhat}

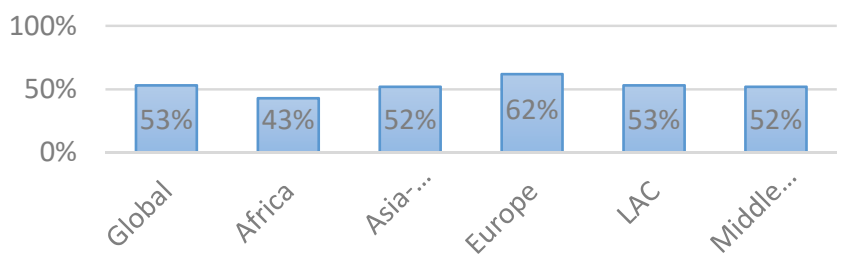

(b)

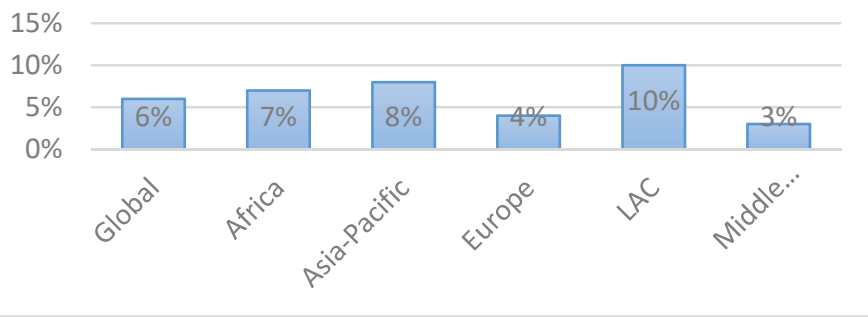

(d)

Figure 5. National initiatives in favor of open educational resources. Source: Adapted from [46]. (a) Yes, very much; (b) Yes, somewhat; (c) Not, nothing much; (d) No, not at all.

Focused on the systemic perspective, in terms of outcomes regarding digital transformation at institutions, respondents were asked about their general perceptions on who is leading the change and what are the main achievements. Figure 6 shows the bar charts of participants' opinions to these aspects for four answer categories, from $\mathrm{a}=$ improved governance of information, to $\mathrm{d}=$ not at this stage). In the leadership consultation in LAC, the main responses were 'New learning pedagogies ...' ' and 'Improved access to scientific knowledge'. In Figure 6, LAC took the lead (79\%) in new learning pedagogies and regarding research through new networks $(60 \%)$.

\subsection{Digital Transformation in Higher Education in LAC: Insights from a Subregional Context}

Focused on a subregional context, in this subsection, we present our subregional results for understanding the similarities and differences in the LAC context in comparative terms. Thus, this part of the research was tested at institutions located in three broad subregions, named as 'North/Central America and the Caribbean' (that is, Mexico, the Dominican Republic, Trinidad and Tobago, and Costa Rica), 'the Andean Region' (i.e., Chile, Colombia, Ecuador, and Peru), and 'the MERCOSUR' (including Brazil, Paraguay, Uruguay, and Argentina: see Table 3).

Reasons for this comparative design include the fact that differences in cultural, historical, and social dimensions may provide institutional and systemic insights on each situation, which might otherwise not be apparent. Furthermore, similarities and differences can be discerned, which can provide theoretical and practical implications for management generally and at each institution (see Table 4). 


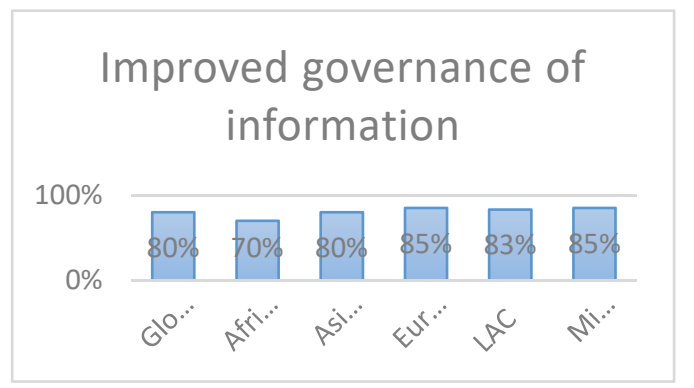

(a)

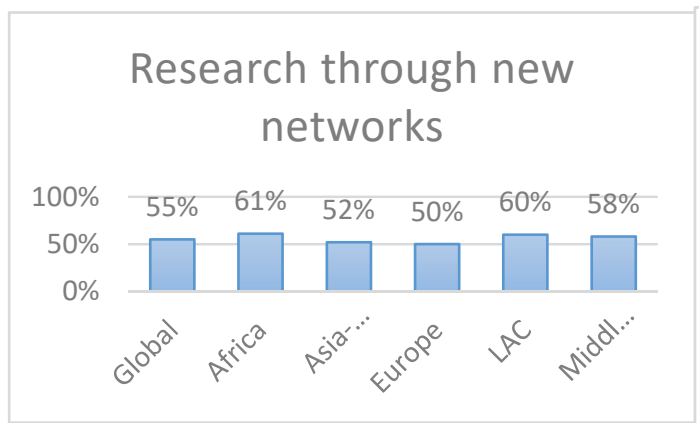

(c)

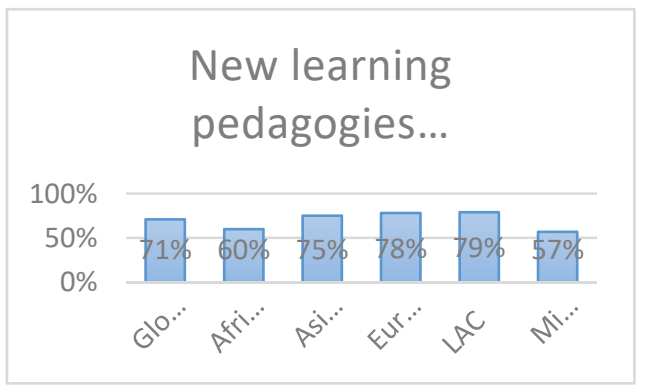

(b)

\section{Improved access to \\ scientific knowledge}

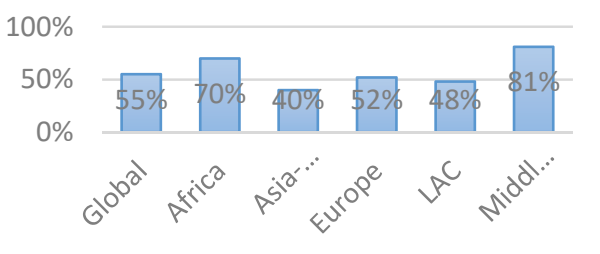

(d)

Figure 6. Key achievements using new technologies. Source: Adapted from [46]. (a) Improved governance of information; (b) New learning pedagogies enhance the student experience and learning outcomes; (c) Improved research through new networks; (d) Improved access to scientific knowledge.

Table 4. Geographical area of the research in LAC (subregions).

\begin{tabular}{cccc}
\hline \multicolumn{2}{c}{ North/Central America and the Caribbean } & The Andean Region & The MERCOSUR \\
\hline \multirow{4}{*}{ Countries } & Mexico & Colombia & Brazil \\
& The Dominican Republic & Ecuador & Uruguay \\
& Costa Rica & Peru & Paraguay \\
& Trinidad and Tobago & Chile & Argentina \\
\hline
\end{tabular}

Source: own elaboration.

In addition to this graphic visualization and the above-mentioned descriptive analysis regarding a worldwide overview, to further investigate our results, the distribution pattern of the data was observed by examining the results of the statistics. The selection of the appropriate statistical test depended on the characteristics of the variables: chi-squared, contingency coefficient, and Cramer's V. Mann-Whitney and Kruskal-Wallis tests were performed considering the data were non-parametric, or when the nature of data was uncertain. The results of these analyses are presented in Table 4 for conventional levels of significance ( $p$-value $<0.05$, where $\mathrm{H}_{0}$ is rejected). The total number of participants in this research was 27 in each subregion, and it involved institutions from several countries.

The results shown in Table 5 revealed that in global terms and for conventional levels of significance, the null hypothesis of homogeneity in the perceptions could be rejected and, therefore, we accept that participants differed about the relevance of digital transformation in higher education institutions depending on the area surveyed. That is, a resistance to digital transformation is evidenced in this research because technology yields many benefits but also exposes people to threats and ethical dilemmas. For example, the widespread adoption of information technologies alongside globalization has led to the emergence of new issues that need to be addressed, including tech addiction, privacy breaches, and the need to adjust business models in response to industry disruptions and automation in higher education institutions. For these reasons, leaders in higher education need to work collectively not only to eliminate the digital divide, but also by granting access to 
technology in terms of its different dimensions, using social media in ways that help them detect misinformation and become digital citizens.

Table 5. Chi-squared statistics for global results and particularities by regions/subregions.

\begin{tabular}{|c|c|c|c|}
\hline Part and Questions (Questionnaire) & $\begin{array}{l}\text { Chi-Squared } \\
\text { (Sig., 2-Sided, } p \text {-Value) }\end{array}$ & $\begin{array}{l}\text { Conting. Coef. } \\
\text { (Value) }\end{array}$ & $\begin{array}{c}\text { Cramer's V } \\
\text { (Value) }\end{array}$ \\
\hline \multicolumn{4}{|l|}{ Part I: institutional and contextual elements } \\
\hline The framework of the system: global results & 0.000 & 0.283 & 0.322 \\
\hline Rest of the world vs. LAC & 0.001 & 0.312 & 0.317 \\
\hline The scope of the system: global results & 0.057 & 0.191 & 0.181 \\
\hline Rest of the world vs. LAC & 0.003 & 0.325 & 0.201 \\
\hline \multicolumn{4}{|l|}{ Part II: digital transformation at higher education institutions } \\
\hline The structure of the system: global results & 0.001 & 0.266 & 0.312 \\
\hline Rest of the world vs. LAC & 0.013 & 0.191 & 0.012 \\
\hline The ecology of the system: global results & 0.002 & 0.213 & 0.261 \\
\hline Rest of the world vs. LAC & 0.001 & 0.201 & 0.228 \\
\hline $\begin{array}{r}\text { Part III: perceptions of the implementation of digital } \\
\text { transformation at institutions }\end{array}$ & $\begin{array}{l}\text { Mann-Whitney } \\
\quad(p \text {-value) }\end{array}$ & \multicolumn{2}{|c|}{ Kruskal-Wallis ( $p$-value) } \\
\hline The operation of the system: global results & - & \multicolumn{2}{|c|}{0.031} \\
\hline North/Central America and the Caribbean vs. Andean Region & 0.001 & \multicolumn{2}{|c|}{-} \\
\hline North/Central America and the Caribbean vs. MERCOSUR & 0.072 & \multicolumn{2}{|c|}{-} \\
\hline Andean Region vs. MERCOSUR & 0.000 & \multicolumn{2}{|c|}{-} \\
\hline The outcome of the system: global results & - & \multicolumn{2}{|c|}{0.000} \\
\hline North/Central America and the Caribbean vs. Andean Region & 0.000 & \multicolumn{2}{|c|}{-} \\
\hline North/Central America and the Caribbean vs. MERCOSUR & 0.002 & \multicolumn{2}{|c|}{-} \\
\hline Andean Region vs. MERCOSUR & 0.021 & \multicolumn{2}{|c|}{-} \\
\hline
\end{tabular}

Source: own elaboration.

Additionally, toward the end of examining these opinions more extensively in comparative terms, we divided the sample between LAC and the rest of the world. The results of the analysis allowed us to conclude that these opinions are generally shared worldwide.

As a result, it is very evident that the institutional and contextual elements linked to digital transformation in higher education institutions are measured in terms of both the framework of a system and the scope of the system - not only worldwide but also in LAC versus the rest of the world. Certainly, this could be a sign of a potential to integrate regulatory and national policies more fully, or maybe that it is important that regulations were considered in strategic plans in institutions. From a systemic perspective for understanding digital transformation in higher education, every country needs to rethink its education system considering the risks and opportunities of digital transformation. Students can benefit from personalized learning environments that incorporate artificial intelligence, gamification, big data, and virtual reality, but institutions require systemic adaptations with the introduction of technology, particularly in LAC. Furthermore, teachers must shift from being instructors to becoming mediators in the classroom; managers and administrators must redefine the roles of formal versus informal education settings, and governments in the LAC region must provide institutional and policy frameworks to take advantage of the knowledge economy and raise living standards. For example, in Paraguay, educational leaders understood that technology must be part of a broader development strategy.

Measuring the implementation of digital transformation in higher education at institutions, in terms of the structure of the system and its ecology, findings revealed a significant difference and relevance of the usage of learning management systems at institutions and changes in teaching pedagogies. The general overview and regional breakdown showed 
that significant differences were found regarding the two main variables identified in this research.

Within this context, respondents were asked to assess their perceptions of the implementation of digital transformation in higher education, measured by the operation of a system and its outcome. Regarding the operation of the system and in terms of the results between North/Central America and the Caribbean versus MERCOSUR, no statistically significant differences were found. However, a significant difference was evidenced in all cases.

Certainly, in the LAC context, international organizations pointed out that the digital transformation needs to be thought about in a systemic way and in the long term, with a consideration of the historical transition of this region and its peculiarities, where changes are developed in a slower way compared to other regions globally [39]. While there has been a substantial transformation in recent years, there are still digital divergences in both homes and companies, which leaves the most vulnerable segments of each country behind $[47,48]$. The technological acceleration caused by COVID-19 is expected to overcome gaps and increase resilience through digital transformation [49].

\section{Conclusions, Contribution, and Prospective}

\subsection{Conclusions}

Nowadays, environments in higher education experience changes due to increasing unpredictability. Educational institutions are diverse in nature and their way of operating according to each context. Especially in Latin America and the Caribbean, where historical journeys and culture mark each country in the region in different ways. Notwithstanding, technology has an important role in competencies and skills demanded by students to join society, as well as on the way to acquire information and knowledge, particularly. Although this transformation is showing up in many styles, means, and opportunities, one important aspect in this line is how to shape higher education in a digital world in a context marked by needs and inequalities, which threaten this transformation.

According to the results described here, the survey revealed that most of the participants in the leadership consultation take digital transformation as a high preference in general. These responses show the trend of leaders in higher education towards the digital transformation of their institutions. A trend that has accelerated with the crisis unleashed by COVID-19, which has forced universities to transform themselves to support their activities and continuity of higher education in the region.

Technological advancement means a fast transformation in higher education. This sort of phenomenon is growing quickly and gained a macroscale by benefiting the growing virtual learning and its global impact in general. Higher education institutions' rising role as a major global actor has lured general attention in both developed and underdeveloped countries. The latter (such as those in the LAC region) are beginning to be aware of the elements that the system must consider to achieve digital transformation. These range from the creation of national policies and agendas that support the transformation in the country to the development of digital skills in teachers and students.

According to the open consultation carried by IAU, it is proven that big differences are needed for seeking technological potential in higher education, such as for internet infrastructure. This evidences an evident menace to future societies and shows the difference in population access. COVID-19 and social distancing measures showed the gaps that exist in terms of access to technology. For example, in Chile, there are social groups whose access to technology is less than that of others. The existence of different educational ecosystems has boosted a discussion related to different technological structures available to higher education institutions in Latin America and the Caribbean.

In this research, various descriptions have been made in order to know how digital transformation works. The review suggests that digital transformation in LAC institutions are aligned with the rest of the world in terms of what is expected of it and that the institutions depending on the country, have several possibilities for advancing transformation. 
For understanding this framework, prejudgments about what the factors of a local educational environment model should be. For instance, all along the trial of generating a particular ecosystem, conjectures about these actions are defined, and the university can have an idea about what is needed to deliver and create. According to the two specific objectives, we conclude that capital is needed to assess parameters and indicators to properly consider different cultural, social, environmental, and economic considerations at higher education institutions. Throughout this article, the digital transformation in higher education institutions has been characterized as a set of dimensions by collecting several sources on an educational digital transformation systemic perspective; as well as an assessment of the main dimensions for understanding this digital transformation from a systemic perspective in Latin America and the Caribbean, in empirical terms, has been offered.

This study provides an analysis from a systemic perspective on digital transformation in LAC. The data highlight the importance of considering different facts in the transformation of higher education institutions, such as the relevance of innovation in the current context. The specific key performance aspects reinforce the importance of managing certain instruments in the most important social, cultural, economic, and environmental dimensions. Furthermore, this study considers some limitations, such as the difficulty to coordinate agents and institutions from different geographical locations and the different visions of the institutions involved in the digital transformation project in particular.

Thus, the existence of technological projects worldwide helps the execution of a quality standard in the arrangement of the digital transformation in institutions and events. From this point of view, the start-up of a systemic perspective in this educational context shows the need to center on various indicators at different levels of management in higher education.

\subsection{Contribution and Prospective}

In this study, some indicators, such as the use and application of technology, allowed the education sector to adapt to the pandemic and assume its costs. Higher education institutions in Latin America and the Caribbean have much to offer both in terms of historical, cultural, and environmental heritage from a digital point of view. Currently, the challenge is being taken up, and the transformation is becoming possible. Implications for understanding digital transformation in higher education institutions are discussed in this work.

This paper will be useful to researchers and managers interested in the systemic forces that shape the way higher education institutions deal with digitalization. From a systemic perspective for understanding digital transformation in higher education, six distinct dimensions were presented and evidenced. Finally, the role of participants and institutions in promoting systemic change is described, and further implications for change agents can be inferred.

Moreover, in this paper, we present a discussion by answering our research question in terms of several contributions. The first relevant contribution of this paper is to overcome the dualistic relationship between institutions and the environment in higher education, considering both as part of an ecosystem based on the combination between six dimensions and their respective constituents. The second contribution is to present this systemic perspective for understanding the immersion of the institution in its respective environment, particularly in LAC. Finally, the third contribution we expose is focused on deepening the existing relationship in order to understand its interconnected systemic structure among regions and subregions in comparative terms.

In addition, in this paper, a relevant finding is that, while all higher education institutions are ruled by national policies, information access happens beyond national boundaries; according to this fact, having an all-embracing platform to reciprocate and debate the manner that new technologies are changing education is preceptive. For managers of educational institutions to understand how a university operates utilizing a technologi- 
cal structure, certain established norms and regulations about the educational ecosystem and field need to be addressed. The first established norm and regulation to be addressed is that higher education institutions are not vision-focused and are only concerned about making utilities. The information found suggests that both public and private higher education institutions need to be vision-oriented and purposive regarding how the staff realizes that mission and its vision. Public universities have published missions similar to those for private and, as the data from the Chilean case suggests, are engaged in taking both operational and strategic policies.

Another contribution to the educational field is that the use of digitalization and technological systems and activities in higher education leads to vision drift. The data suggests that institutions should adopt a systemic perspective or include certain best practices of digital transformation from other contexts.

Higher education institutions and universities should ponder which digitalization strategy helps the institution best accomplish its vision. A university should not consider a structure just because it believes it will make the institution more technologically stable. Universities in Latin America could join similar digital activities making a relevant social contribution out of it.

Author Contributions: All authors listed have made a substantial, direct, and intellectual contribution to this research. L.M.C.S. designed the study, wrote the paper, and analyzed the data. L.M.C.S. and K.N.-V. wrote all the document. S.Q.y.A. reviewed the entire document. All authors have read and agreed to the published version of the manuscript.

Funding: A previous version of this research received the ESIC Best Paper Award in Digital Transformation, 35th Annual Meeting of the European Academy of Management and Business Economics (AEDEM). The APC was partially funded by the Universidad de Las Américas (Chile).

Institutional Review Board Statement: Ethical review and approval was not required for the study on human participants in accordance with the national legislation and institutional requirements.

Informed Consent Statement: Written informed consent from the participant was not required to participate in this study in accordance with the national legislation and the institutional requirements.

Data Availability Statement: The datasets generated for this study are available on request to the corresponding author.

Acknowledgments: The authors would like to express their gratitude to Universidad de Las Américas, ESIC, and AEDEM for providing technical and financial support in this paper.

Conflicts of Interest: The authors declare no conflict of interest.

\section{References}

1. Cornell University; INSEAD; WIPO. The Global Innovation Index 2019: Creating Healthy Lives-The Future of Medical Innovation, 2019; Cornell University: Ithaca, NY, USA; INSEAD: Fontainebleau, France; WIPO: Geneva, Switzerland, 2019.

2. Hildebrand, C. Ray Wang: Cloud Is the Foundation for Digital Transformation. Available online: https://www.forbes.com/sites / oracle/2014/12/19/ray-wang-cloud-is-the-foundation-for-digital-transformation/ (accessed on 30 October 2020).

3. Andree, T. Human Needs in a Digital World. Digital Society Index 2019. Dentsu Aegis Network. Available online: ht tps:/ / www.oxfordeconomics.com/recent-releases/digital-society-index-2019-human-needs-in-a-digital-world (accessed on 30 October 2020).

4. $\quad$ Becker, A.; Cummins, M.; Davis, A.; Freeman, A.; Hall Giensinger, C.; Ananthanarayanan, V. NMC Horizon Report: 2017 Higher Education Edition; The New Media Consortium: Austin, TX, USA, 2017.

5. Saleh, A.; Watson, R. Business excellence in a volatile, uncertain, complex and ambiguous environment (BEVUCA). TQM J. 2017, 29, 705-724. [CrossRef]

6. Fletcher, G.; Griffiths, M. Digital Transformation during a Lockdown. Int. J. Inf. Manag. 2020, 55, 102185. Available online: http:/ / www.sciencedirect.com/science/article/pii/S0268401220310288 (accessed on 30 December 2020). [CrossRef]

7. UNESCO. Understanding Creative Industries: Cultural Statistics for Public Policy Making. Available online: http:/ / portal.unesc o.org/culture/en/files/30297/11942616973cultural_stat_EN.pdf/cultural_stat_EN.pdf (accessed on 30 June 2020).

8. López, A.M. Avance de la Economía Digital en España y retos pendientes. In Economistas. España 2018; Un Balance, núm. ExtraMarzo: Madrid, Spain, 2018; Volume 162-163, pp. 37-46.

9. Rodríguez-Abitia, G.; Bribiesca-Correa, G. Assessing Digital Transformation in Universities. Future Internet 2021, 13, 52. [CrossRef] 
10. Accenture. Digital Transformation Initiative; Accenture, World Economic Forum Analysis: Geneva, Switzerland, 2018.

11. Ravarini, A.; Locoro, A.; Martínez, M. Digital Transformation Projects Maturity and Managerial Competences: A Model and Its Preliminary Assessment. Lect. Notes Inf. Syst. Organ. 2020, 33, 259-275. Available online: https: //www.researchgate.net/profile/Michele_Kosremelli_Asmar/publication/330425949_Meta_Principles_of_Technology_Acces sibility_Design_for_Users_with_Learning_Disabilities_Towards_Inclusion_of_the_Differently_Enabled/links/5d6cb96da6fdc c547d721869/Meta-Principles-of-Technology-Accessibility-Design-for-Users-with-Learning-Disabilities-Towards-Inclusionof-the-Differently-Enabled.pdf\#page=259 (accessed on 23 December 2020).

12. Fenton, A.; Fletcher, G.; Griffiths, M. Strategic Digital Transformation: A Results-Driven Approach; Routledge: London, UK, 2020.

13. Tiffin, J.; Rajasingham, L. The Global Virtual University; Routldge-Falmer: London, UK, 2009.

14. Davenport, T.H.; Westerman, G. ¿Por qué Fracasaron las Transformaciones Digitales de General Electric y Nike? Harvard Business Review en Español. 2019. Available online: https://hbr.es/modelos-de-negocio/1309/por-qu-fracasaron-las-transformacionesdigitales-de-general-electric-y-nike (accessed on 30 October 2020).

15. Dell Technologies. Digital Transformation Index II, Dell Technologies, Intel; Vanson Bourne Publishing: Newbury, UK, 2018.

16. Llorens, F.; Fernández, A. Aproximación a una Medida de la Transformación Digital de las Universidades, El Blog de Studia XXI, Universidad: Una Conversación Pública Sobre la Universidad. 2018. Available online: https://www.universidadsi.es/aproximac ion-a-unamedida-de-la-transformacion-digital-de-las-universidades / (accessed on 30 November 2020).

17. Fernández, A.; Llorens, F.; Juiz, C. Cómo Priorizar los Proyectos TI Estratégicos para tu Universidad; Universidad de Alicante: Alicante, España, 2018. Available online: http:/ / rua.ua.es/dspace/handle/10045/86867 (accessed on 30 October 2020).

18. Reuters. The World's Most Innovative Universities. 2018. Available online: https://www.reuters.com/article/us-amers-reu ters-ranking-innovative-univ / reuters-top-100-the-worlds-most-innovative-universities-2018idUSKCN1ML0AZ (accessed on 21 June 2020).

19. Reuters. Europe's Most Innovative Universities 2019. Available online: https://graphics.reuters.com/EUROPE-UNIVERSITYIN NOVATION/010091N02HR/index.html (accessed on 21 June 2020).

20. Rodríguez, M.J.; Fernández, S.; Rodeiro, D. Innovation in cultural and creative industries firms with an academic origin (CCI-USOs): The role of regional context. Technovation 2018, 92, 102044. [CrossRef]

21. Wallace, M. Digital Risks on Why the Best Business Continuity Plans Are Usually the Simplest. 15th MayInsurance Business Magazine. 2020. Available online: https://www.insurancebusinessmag.com/uk/news/technology/digital-risks-on-why-the -best-business-continuity-plansare-usually-the-simplest-222533.aspx (accessed on 30 October 2020).

22. Pedroza, R. The university 4.0 with intelligent curriculum 1.0 in the fourth industrial revolution. Rev. Iberoam. Para La Investig. Y El Desarro. Educ. RIDE 2018, 9, 168-194.

23. Siemens, G.J. Connectivism: A Learning Theory for the Digital Age. Int. J. Instr. Technol. Distance Learn. $2005,2,1-9$.

24. Alexander, B.; Ashford-Rowe, K.; Barajas-Murphy, N.; Dobbin, G.; Knott, J.; McCormack, M.; Weber, N. Horizon Report: 2019; Higher Education Edition; EDUCAUSE: Louisville, CO, USA, 2019; p. 44.

25. Castro Benavides, L.M.; Tamayo Arias, J.A.; Arango Serna, M.D.; Branch Bedoya, J.W.; Burgos, D. Digital Transformation in Higher Education Institutions: A Systematic Literature Review. Sensors 2020, 20, 3291. [CrossRef]

26. Núñez-Valdés, K.; Alpera, S.Q.; Cerdá Suárez, L.M. An Institutional Perspective for Evaluating Digital Transformation in Higher Education: Insights from the Chilean Case. Sustainability 2021, 13, 9850. [CrossRef]

27. Grech, A.; Camilleri, A.F. Blockchain in Education; EUR: London, UK, 2017.

28. Seres, L.; Pavlicevic, V.; Tumbas, P. Digital Transformation of Higher Education: Competing on Analytics, 2019. In Proceedings of the 12th International Technology, Education and Development Conference (INTED2018), Valencia, Spain, 5-7 March 2018; Chova, L.G., Martínez, A.L., Torres, I.C., Eds.; pp. 9491-9497. [CrossRef]

29. Halloun, I. Mind, Brain, and Education: A Systemic Perspective; Working paper; H Institute: Jounieh, LB, USA, 2016.

30. Bunge, M. Systemism: The alternative to individualism and holism. J. Socio-Econ. 2000, 29, 147-157. [CrossRef]

31. Laszlo, A. Living systems, seeing systems, being systems: Learning to be the system that we wish to see in the world. Spanda J. Syst. Change 2015, 6, 165-173.

32. Liu, J.; Mooney, H.; Hull, V.; Davis, S.J.; Gaskell, J.; Hertel, T.; Lubchenco, J.; Seto, K.C.; Gleick, P.; Kremen, C.; et al. Systems integration for global sustainability. Science 2015, 347, 963. [CrossRef] [PubMed]

33. Waters Foundation. The Impact of the Systems Thinking in Schools Project: 20 Years of Research, Development and Dissemination; White Paper; Waters Foundation: Pittsburgh, PA, USA, 2010.

34. Dewar, J. University 4.0: Redefining the Role of Universities in the Modern Era, 2017, Higher Education. Available online: https:/ / www.thehighereducationreview.com/magazine/university-40-redefining-the-role-of-universities-in-themoder n-era-SUPG758722027.html (accessed on 3 August 2020).

35. Mundial, B. Informe Sobre el Desarrollo Mundial 2019: La Naturaleza Cambiante del Trabajo; Banco Mundial: Washington, DC, USA, 2019.

36. Comisión Económica para América Latina y el Caribe (CEPAL). Tecnologías Digitales Para Un Nuevo Futuro, (LC/TS.2021/43); Comisión Económica para América Latina y el Caribe (CEPAL): Santiago, Chile, 2021.

37. Comisión Económica para América Latina y el Caribe (CEPAL). Datos Y Hechos Sobre La Transformación Digital, Documentos de proyectos (LC/TS.2021/20); Comisión Económica para América Latina y el Caribe (CEPAL): Santiago, Chile, 2021. 
38. IESALC. ¿Cerrar Ahora Para Reabrir Mejor Mañana? La Continuidad Pedagógica En Las Universidades De América Latina Durante La Pandemia; IESALC: Paris, France, 2021.

39. OECD. Perspectivas Económicas de América Latina 2020: Transformación Digital Para una Mejor Reconstrucción; OECD Publishing: Paris, France, 2020. [CrossRef]

40. Viñals, A.; Cuenca, Y.J. El rol del docente en la era digital. Rev. Interuniv. Form. Profr. 2016, 30, $103-114$.

41. OECD. Making the Digital Transformation in Latin America and the Caribbean; OECD Publishing: París, France, 2019. [CrossRef]

42. McIndoe, R. Why Are People panic Buying Toilet Roll? Whether There Is a Toilet Roll Shortage and Which Supermarkets Are Limiting Supplies. Available online: https:/ / www.scotsman.com/health/why-are-people-panic-buying-toilet-roll-whether-ther etoilet-roll-shortage-and-which-supermarkets-are-limiting-supplies-2445943 (accessed on 2 November 2020).

43. OECD. Índice de Gobierno Digital OCDE 2019: Resultados y Mensajes Claves. 2020. Available online: http://www.oecd.org/g ov / digital-government/digital-government-index-2019-highlights-es.pdf (accessed on 2 December 2020).

44. Moraña, M. Transculturación y Latinoamericanos; Cuadernos de Literatura Vol. XXI N. 41. 2017. Available online: https: / / dialnet.unirioja.es/descarga/articulo/6041360.pdf (accessed on 2 November 2020).

45. Leyton, M.J. La Gestión Transcultural: Un Cambio de Paradigma Para las Nuevas Relaciones Politico-Culturales Con Las Comunidades Participati-vas; 2020. Available online: http://observatoriocultural.udgvirtual.udg.mx/repositorio/handle/123456789/1004 (accessed on 2 November 2020).

46. Jensen, T. Higher Education in the Digital Era. In The Current State of Transformation around the World in the Digital Era; International Association of Universities (IAU): Paris, France, 2019.

47. Burgos, D.; Branch, J.W. (Eds.) Radical Solutions for Digital Transformation in Latin American Universities, Lecture Notes in Educational Technology; Springer Nature: Basingstoke, UK, 2021. Available online: https://doi.org/10.1007/978-981-16-3941-8_1 (accessed on 2 November 2020).

48. Giesenbauer, B.; Tegeler, M. The Transformation of Higher Education Institutions towards Sustainability from a Systemic Perspective. In Universities as Living Labs for Sustainable Development. World Sustainability Series; Leal Filho, W., Lange Salvia, A., Pretorius, R., Londero, L., Manolas, E., Alves, F., Azeiteiro, U., Rogers, J., Shiel, C., Do Paco, A., Eds.; Springer: Cham, Germany, 2020. [CrossRef]

49. Salazar-Xirinachs, J. Transformación Digital, Reactivación Económica y Empleo en América Latina y el Caribe Post-COVID-19. 2021. Available online: http:/ / riacevents.org/gtecs/wp-content/uploads/2021/02/ESP-TD-y-su-papel-en-promover-la-rea ctivacion-con-transformacion-en-AL.pdf (accessed on 20 October 2021). 